\title{
RESEARCH ON LOGISTICS PROBLEMS OF NETWORK MARKETING FOR FRESH AGRICULTURAL PRODUCTS BASED ON "INTERNET +"
}

\author{
Huan Wang \\ Hubei University of Automotive Technology, P.R.China
}

\begin{abstract}
Nowadays, the network marketing of fresh agricultural products has become a new trend. But its logistics still shows many problems, mainly including unscientific logistics organization, low conjunction between network marketing platforms and logistics links, and lack of specialized third party logistics(TPL) enterprises. Based on the "Internet + ", this paper puts forward three pertinence proposals, such as establishing effective logistics organization pattern, promoting the conjunction between network marketing platforms and logistics links, fostering specialized TPL enterprises. By taking good advantage of "Internet + ", the logistics problems of network marketing for fresh agricultural products can be solved and the level of agricultural specialization and infrastructure construction in China can be constantly improved.
\end{abstract}

Keywords: "Internet +", Fresh Agricultural Products, Network Marketing, Logistics

JEL code: M0， O0，Q0

\section{Introduction}

In recent years, accompanied by frequent food safety incidents and rapid development of the Internet, the network marketing for fresh agricultural products has achieved a flourishing development. The fresh agricultural produce e-commerce emerged in succession, such as womai.com, tony's farm, tootoo.cn, etc. Since 2013, some e-commerce giants, including Tmall, Jingdong, YHD.com and Suning, have marched into the field as well. From 2012 to 2016, the scale of China's fresh produce e-commerce market is as follows. 


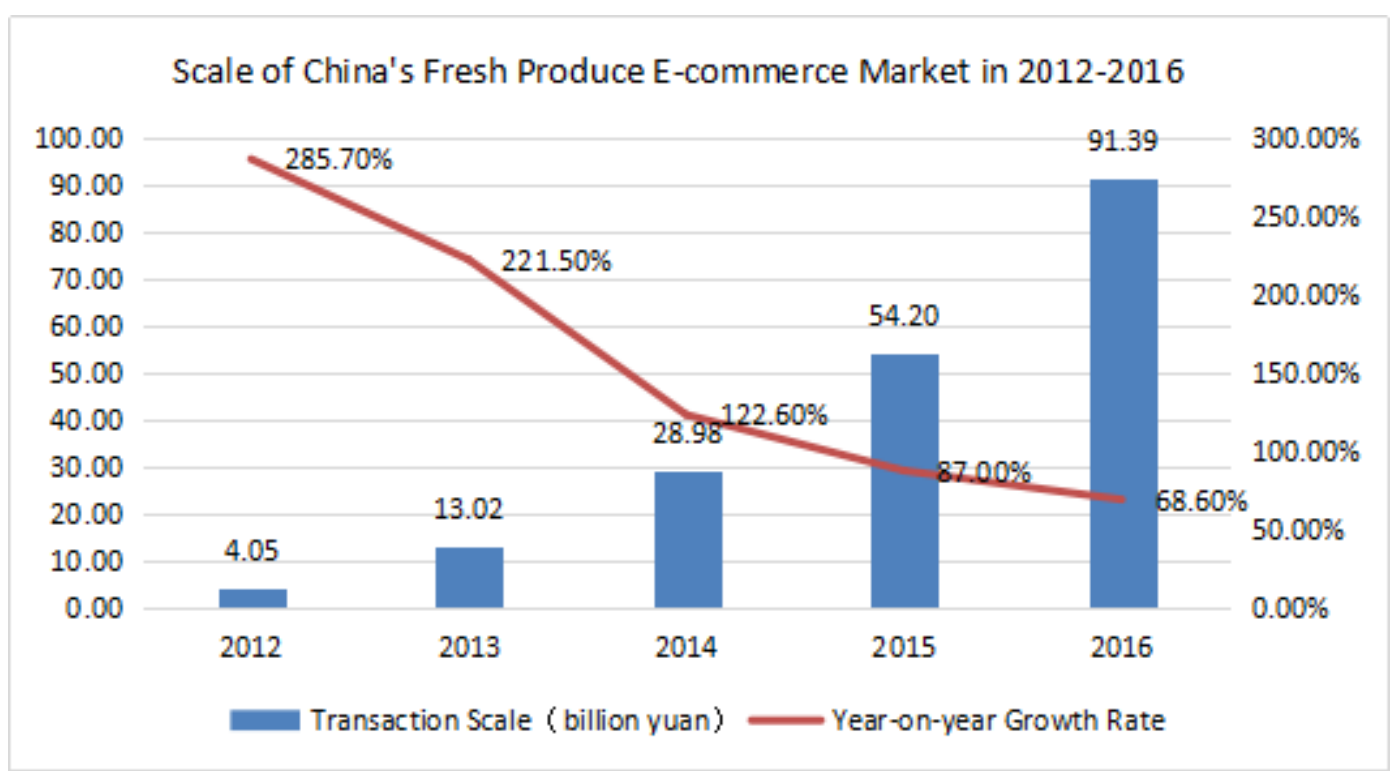

Figure 1. Scale of China's Fresh Produce E-commerce Market in 2012-2016

At present, the distribution areas of fresh agricultural produce have also extended from the first-tier cities to the second and third-tier cities. However,due to the unique characteristics of fresh agricultural products, its logistics shows many problems, such as asymmetric market information, low level of logistics services, underdeveloped logistics functions, etc, which have become the bottleneck of fresh agricultural product network marketing.

The influence of "Internet + " on traditional logistics industry mainly embodied in two points. One is the simplification of troublesome links and procedures for traditional logistics via internet tools. Second is reducing the cost of communication and customer service, and further strengthening the ability of developing new sales channels in the existing market.

In order to improve the innovation and productivity of the real economy, the "Internet + " plan combines the internet thinking with technology, integrates tangible resources with intangible resources, provides value-added services, innovates marketing patterns and operation mode.

Therefore, in this era, the implementation of "Internet +" plan is an inevitable trend of modern logistics transformation and upgrading, and also a key to solve the logistics bottlenecks of fresh agriculture products under the network marketing.

\section{Overview on the Logistics of Network Marketing for Fresh Agricultural Products}

\subsection{The Concept of Network Marketing for Fresh Agricultural Products}

The narrow concept of fresh agricultural products refers to primary agricultural products which are produced (planting or breeding) by farmers or agricultural production enterprises with a little or no primary processing. They are human consumption and difficult to keep in normal temperature for a long time, such as vegetables, fruit, livestock, aquatic products, etc. The broad concept includes primary fresh produce, freeze and refrigerate fresh produce, 
processing fresh produce, etc. In this paper, the concept of fresh agricultural products mainly extends from the narrow sense to some processing fresh produce.

The network marketing of fresh agricultural products is a marketing mode based on internet, using text, image, voice and other information carriers to interact with customers. It is different from online sales. The network marketing of fresh agricultural products pursues the combination of online and offline, the interleaving of the internet and reality, and the mutual feedback of behavior and information.

\subsection{Logistics Features of Network Marketing for Fresh Agricultural Products}

As an agricultural country, in recent years, the government has issued a series of policies and established some new types of agriculture organizations, which are favorable to the application of new technology for agricultural development, and constantly improving the level of agricultural specialization and infrastructure construction. They all make the agricultural production increase year by year. The logistics features of network marketing for fresh agricultural products are as follows.

First, high distribution quality. As the return or exchange of goods often costs much more time and money, the process of product packaging and distribution requires a higher standard in both logistics technology and equipment. For example, if the fruit that consumers receive is not fresh, the consumers will complain. If the meat products was refunded, they definitively lose their lives.

Second, high time efficiency. As we all known, Fresh agricultural produce is vulnerable and perishable, especially in summer. Once beyond the preservation period, the products will soon lose their value-in-use.

Third, high expectation of customer experience. Generally speaking, consumers don't care about the strange logistics at all. Their attention has always been associated directly with the end distribution service. The network marketing lacks of customer experience, because the fresh agricultural products are difficult to touch, smell or taste. So as the only way to contact with consumer face to face, the end distribution must have a better service.

Fourth, the decentralization of end distribution. The demand of fresh agricultural products is characterized by seasonal periodicity and geographical agglomeration, so its network marketing relies more on the expertise of logistics distribution.

Fifth, high logistics costs. For the above reasons, no doubt, the logistics costs increased. In particular, the bad storage of fresh agricultural products can lead to more losses. And domestic traditional agricultural attaches importance to production and make light of circulation, which result in enormous logistics cost. 


\section{Analysis of Logistics Status of Network Marketing for Fresh Agricultural Products}

Fresh agricultural products are mainly produced in rural areas, but consumption capacity of rural areas is limited. So it is necessary to push fresh agricultural products to cities to achieve higher market value. The network marketing can solve this problem. However, most of the rural areas in China only have undeveloped transport infrastructures, and lack of transport lines for fresh agricultural products, which can waste amount of fresh agricultural products. Therefore, Logistics status of network marketing for fresh agricultural products is not optimistic.

\subsection{Unscientific Logistics Organization}

Once upon a time, fresh agriculture products cold chain was also the blue sea in the eyes of e-commerce. But now we have the data to show that, in over 4000 fresh produce e-commerce suppliers across the country, only $1 \%$ can achieve profitability, $4 \%$ are basically flat, $88 \%$ post a small loss, and the remaining $7 \%$ is in a huge deficit. The reason to form this situation may be many-sided, but the unscientific logistics organization is one of the reasons to be trifled with. The network marketing modes for fresh agricultural products are diversified, but there is no strategic alignment among the pattern bodies. The transmission of information and resources for logistics operation are blocked. Its network marketing modes are unable to cope with logistics service demand and operation risks.

\subsection{Low Conjunction between Network Marketing Platforms and Logistics Links}

During the process of network marketing, most merchants agree on a shipping agreement with logistics companies after they have reached a deal with customers through online platforms. In this way, merchants and customers are unable to track the logistic status, leaving a hidden danger. Especially in the procurement and transportation of some bulk fresh products, the low conjunction between network marketing platforms and logistics links results in slow customer receipt and low satisfaction. Thus, a completeness of fresh agricultural products e-commerce should be able to search social logistics resources online. The online collaborative between logistics and platform should be high enough. And most of the anomalies and logistic problems can be captured by network marketing platforms and fed back to businesses and consumers.

\subsection{Lack of Specialized Third Party Logistics Enterprises}

There are two main types of logistics in network marketing of fresh agricultural product. They are self-support logistics and the third-party logistics (TPL). The former applies to the enterprises which may have abundant resources and strong strength. Rather than rely on some unprofessional TPL enterprises, they trust more on themselves. In this way, they can control the whole logistics process and make the company nearer to the customers. Inevitably, the self-support logistics may divert resources and bring more risks. 
However, most enterprises prefer to cooperate with TPL enterprises. Because the characteristics of fresh agricultural product require more advanced technology and equipment, and the logistics of fresh agricultural products requires low consumption, low temperature and high efficiency. Many TPL enterprises are unable to expand into the cold chain logistics industry. In 2016, the market size of the cold chain logistics is estimated at 200 billion and is $22.3 \%$ higher than 2015. In this way, the TPL companies are weak in both technology and management. They are generally not good at the field of fresh agricultural products logistics and lack of coordination with sellers. After receiving the order, the TPL companies first collect the fresh agricultural products from the merchant, and then packaging, transportation, loading and unloading and distribution. Some unprofessional TPL companies can easily create problems in this process, such as food spoilage, which increase the loss to both merchants and consumers. So many sellers cannot sell their fresh agricultural products in time, consumers cannot enjoy the high quality products in time as well, let alone the mutual game playing among TPL enterprises, sellers and consumers. In order to chasing lower costs and high profits, the TPL enterprises often ignore consumer experience and only complete the low level of logistics services, which make the sellers helpless and gain bad reputation. Obviously, this situation is not conducive to industry development.

\section{Countermeasures}

In the context of "Internet + ", resources can be integrated by information and big data, and the transaction of fresh produce will change from offline to online, which means not only the adjustment of the usage habit, but also an interest game. Therefore, the interested parties need to find a contract to guarantee the benefits of all parties.

\subsection{Establishing Effective Logistics Organization Pattern}

Based on the "Internet +", the sellers of fresh agricultural products and logistic companies can share their information in a professional public platform, which makes big data become possible. Then, the sellers' demand and the logistic companies' supply can make a better match in the whole field. To be specific, the "Internet + efficient logistics" can be realized by "Internet + efficient transport", "Internet + intelligent storage", "Internet + easy ship", "Internet + wisdom logistics". For example, to solve the "last mile" problem, logistics enterprises can develop joint distribution, centralized distribution, and intelligent distribution, and promote sharing economic model. In this way, the logistics resources of the whole society can be properly integrated

On the other hand, under the internet environment, the construction of logistics park for fresh agricultural products can realize the rational allocation of logistics resources. In addition to the traditional offline trading, the logistics park will also introduce the park information platform and network marketing platform. And cultivating the sellers' online trading habits to extend their business scope. The park managers should try to realize the $\mathrm{O} 2 \mathrm{O}$ model by the combination of offline site management and online platform to operation. The logistics park platform can undertake the storage, processing, packaging and sales of the products. The 
information sharing platform is ready for both logistic supply-side and demand-side. The logistics provider mainly undertakes the logistics distribution function. By doing this, they can reduce the management cost, provide value appreciation service.

\subsection{Promoting the Conjunction between Network Marketing Platforms and Logistics Links}

No matter realizing network marketing or not, enterprises usually sell fresh agriculture products in three ways. They are proprietary e-commerce sales platform, the third party e-commerce sales platform, and offline sales platform. Their specific methods are as follows.

Table 1. Types of sales platforms

\begin{tabular}{c|l}
\hline $\begin{array}{c}\text { Types of sales platforms } \\
\begin{array}{c}\text { Proprietary e-commerce } \\
\text { sales platform }\end{array}\end{array}$ & $\begin{array}{l}\text { Enterprises build e-commerce platform all by themselves to display and sell } \\
\text { products. Then products will be delivered to identified location through the } \\
\text { self-support logistics or the third-party logistic system. }\end{array}$ \\
\hline $\begin{array}{c}\text { The third party e-commerce } \\
\text { sales platform }\end{array}$ & $\begin{array}{l}\text { Paying usage fee, enterprises descend on the third party e-commerce platform to } \\
\text { conduct products display, publicity and sale. By taking advantages of the } \\
\text { platform's promotion, they can increase the number of page views and sales } \\
\text { volume. }\end{array}$ \\
\hline Offline sales platform & $\begin{array}{l}\text { Enterprises follow the traditional ways, such as stores. They make "one-to-one" } \\
\text { interactive communication through the traditional sales channels. }\end{array}$ \\
\hline
\end{tabular}

Under the background of "internet+", the offline sales platform is transforming into the other two kinds of sales platforms. So for a thorough fresh agricultural products e-commerce, the online collaborative between the platform and logistics should be high enough.

First, strengthen the use of the logistics information technology. The fresh agricultural produce should be tracked in real time from the stock, delivery to the receipt. Their logistics status should be timely updated and uploaded to the cloud to facilitate the search of merchants and users. So the platform can also capture most anomalies and logistic problems. Then formatting a feedback to both businesses and consumers.

Second, provide suitable processing and transportation refrigeration temperature for different kinds of fresh agricultural produce, standardize commodities' packaging specifications, and determine the quality inspection standard for different kinds of fresh agricultural produce to guarantee the quality of fresh agricultural products.

Third, focus on the logistics operating norms and technical standards of fresh agricultural products. In order to ensure that the fresh agricultural products' quality and logistics, it is necessary to set up a perfect general quality control system and promote the quality and safety certification and market access system. 
There are some successful examples, such as Motion optimization. As is known to all, SF Express is a logistics company and its main business is express delivery. So the Motion optimization promotes a better conjunction between network marketing platforms and logistics links. From sale orders to customers receiving, Motion optimization has a complete set of standards and guidelines. Its e-commerce platform and logistics link can form information matching and high degree of interaction.

\subsection{Fostering Specialized TPL enterprises}

For some sellers, who are unable to build their own self-support logistics, or cannot take too much time to build the own self-support logistics, the specialized TPL enterprises will be a great choice. No matter for the sellers, TPL enterprises, or between them, they should pay attention to collaborative operation and make full use of the load of transport capacity. Then, all parties can save both time and cost, and improve consumers' satisfaction. In order to better serving network marketing for "Internet + fresh agricultural products" . The existing third party logistics enterprises should develop to cold chain logistics, and become more specialized and efficiency. According to the different characteristics of fresh agricultural products, the TPL enterprises may choose the corresponding logistics facilities and equipment.

To develop the cold chain logistics, enterprises have to strengthen their infrastructure construction, especially increase the coverage of cold chain logistics. At present, the low coverage of cold chain logistics is mainly due to the decentralization of fresh agricultural products. Now the long-distance transportation can realize a low temperature through the whole journey, while the nodes in the logistics process often lose temperature control. So after many transactions, so bad phenomenon will show up, such as melting and rotting. The effects of the cold chain logistics are greatly reduced, let alone more than $80 \%$ products keeping and circulating under normal temperature. The data shows that the loss rate of fruits and vegetables in the process of picking, transporting and storing is $25 \% \sim 30 \%$ in China, while the number in developed countries is under 5\%. So fostering specialized TPL enterprises, especially the cold chain logistics, requires focus on not only the lines of logistics, but also the nodes.

\section{Conclusion}

Above all, solving the logistics problems of network marketing for fresh agricultural products still has a long way to go. The trend of its logistics process mostly transforms from the bulk purchase logistics to small and fast delivery logistics. The quantity of fresh agricultural products also transforms from large to small, may be further refined. In the network marketing of fresh agricultural products, as a sales tool, logistics has a delicate relationship with merchants and consumers. At present, we can harmonize these relations by establishing effective logistics organization pattern, promoting the conjunction between network marketing platforms and logistics links, and fostering specialized tpl enterprises. Under the background of "Internet +", we can foresee the integration among logistics, internet marketing, 
big data and sharing economy. Because of the limit of time, energy and space, the other aspects will be considered in the further research. The e-commerce of fresh agricultural products will well-perform under the support of logistics.

\section{References}

Bo Yan (2015) "Sustainable development of the fresh agricultural products supply chain through the application of RFID technology", Information Technology and Management, vol. 1 .

Guan, Y., Zhong W. L. \& Xu, P. (2015) “Analysis on the Development of Fresh Agricultural Products Logistics in the O2O Mode", Logistics Engineering And Management, vol. 37(11), pp. 82-84.

Lin, H. D. \& Gao, G. J. (2017) "Transportation Safety Countermeasure Analysis on Cold-Chain Logistics of Fresh Agricultural Products", Advanced Materials Research, vol. 651, pp. 3123-3127.

Wang, H. Z. (2013) “Analysis on Logistics Operation Mode of Fresh Vegetables”, Applied Mechanics and Materials, vol. 347, pp. 1084-1086.

Tang, J. (2014) "Research on Planning of Logistics Park Information Platform Based on Internet” Applied Mechanics and Materials, vol. 556, pp. 5787-5789.

Sun, J. (2015) "Study on the E-Commerce Logistics Distribution Modes of Fresh Agricultural Products", Applied Mechanics and Materials, vol. 744.

Laguerrea O., Hoanga H. M. \& Flickb D. (2013). "Experimental Investigation and Modelling in the Food Cold Chain: Thermal and Quality Evolution", Trends in Food Science \& Technology, vol. 2013 (2), pp. 87-97.

Marlies de Keizer (2017) "Logistics network design for perishable products with heterogeneous quality decay”, European Journal of Operational Research, vol. 10.

Ma Jian (2017) "Research on Fresh Products Cold-chain Logistics Mode”, Value Engineering, vol. 22(036), pp. 89-91.

Wang X. H. \& Zhang Q. L. (2016) "Construction of Cold - Chain Logistics System for Fresh Agricultural Products Based on the Internet of Things: Framework Mechanism and Path", Journal of Nanjing Agricultural University (Social Sciences Edition), vol. 16(1), pp. 31-40.

Zhu, W. W., Stephen C. H. Ng, Wang, Z. Q. \& Zhao, X. D. (2017) "The role of outsourcing management process in improving the effectiveness of logistics outsourcing", International Journal of Production Economics, 2017.03.004. 
Zhou, X. J. (2016) "Study on the Connotation and Development Trend of Internet plus Logistics", Business and Globalization, vol. 4(2), pp. 31-36.

Weng, X. G. (2015) "The Analysis of the Development Situation and Trend of the City-Oriented Cold Chain Logistics System for Fresh Agricultural Products", Open Journal of Social Sciences, vol. 11.

Weng, X. G. (2015) "Research on Fresh Agricultural Products Cold Chain Logistics Certification System", iBusiness, vol. 04.

Zhou, X.J. \& Huang, S.N. (2015) "Value Chain Analysis and Reconstruction of Internet plus Logistics”, E-Commerce Letters, 4, pp. 26-30. 